\title{
Recreational physical activity and risk of papillary thyroid cancer among women in the California Teachers Study
}

\author{
Stephanie Whisnant Cash, PhD a,b, Huiyan Ma, PhD ${ }^{c}$, Pamela L. Horn-Ross, PhD ${ }^{d}$, Peggy \\ Reynolds, PhD $^{d}$, Alison J. Canchola, MS ${ }^{d}$, Jane Sullivan-Halley, BS $^{c}$, Shirley A.A. \\ Beresford, PhD ${ }^{a, b}$, Marian L. Neuhouser, PhD ${ }^{a, b}$, Thomas L. Vaughan, MD ${ }^{a, b}$, Patrick J. \\ Heagerty, $\mathbf{P h D}^{\mathrm{e}, \mathrm{b}}$, and Leslie Bernstein, $\mathbf{P h D}^{\mathrm{c}}{ }^{*}$ \\ aDepartment of Epidemiology, School of Public Health, 1959 N.E. Pacific Street, Box 357236, \\ University of Washington, Seattle, WA 98195 \\ bPublic Health Sciences Division, Fred Hutchinson Cancer Research Center, 1100 Fairview Ave \\ North, Seattle, WA 98109 \\ 'Division of Cancer Etiology, Department of Population Sciences, Beckman Research Institute, \\ 1500 East Duarte Road, Population Science Building 173, City of Hope, Duarte, CA, 91010 \\ ${ }^{d}$ Cancer Prevention Institute of California, 2201 Walnut Avenue, Suite 300, Fremont, CA 94538 \\ eDepartment of Biostatistics, School of Public Health, 1959 N.E. Pacific Street, University of \\ Washington, Seattle, WA
}

\section{Abstract}

Purpose-Little is known about the relationship between physical activity and thyroid cancer risk, and few cohort data on this association exist. Thus, the present study aimed to prospectively examine long-term activity and risk of papillary thyroid cancer among women.

Methods-116,939 women in the California Teachers Study, aged 22 to 79 years with no history of thyroid cancer at cohort entry, were followed from 1995-1996 through 2009; 275 were diagnosed with invasive papillary thyroid cancer. Cox proportional-hazards regression provided relative risk (RR) estimates and 95\% confidence intervals (CI) for associations between thyroid cancer and combined strenuous and moderate recreational physical activity both in the long-term (high school through age 54 years or current age if younger than 54 years) and recently (during the three years prior to joining the cohort).

Results-Overall, women whose long-term recreational physical activity averaged at least 5.5 MET-hours/week (i.e. were active) had a non-significant $23 \%$ lower risk of papillary thyroid cancer than inactive women ( $R R=0.77,95 \% \mathrm{CI}: 0.57,1.04)$. RR estimates were stronger among normal weight or underweight women (body mass index, BMI $<25.0 \mathrm{~kg} / \mathrm{m}^{2}$, trend $p=0.03$ ) than among overweight or obese women (trend $p=0.35$; homogeneity-of-trends $p=0.03$ ). A similar

\footnotetext{
(C) 2012 Elsevier Inc. All rights reserved.

*Correspondence to: Leslie Bernstein, PhD, Division of Cancer Etiology, Department of Population Sciences, Beckman Research Institute, City of Hope, 1500 East Duarte Road, Building 173, Duarte, CA 91010, Phone: (626) 471-7315; Fax: (626) 471-7308. LBernstein@coh.org.

Publisher's Disclaimer: This is a PDF file of an unedited manuscript that has been accepted for publication. As a service to our customers we are providing this early version of the manuscript. The manuscript will undergo copyediting, typesetting, and review of the resulting proof before it is published in its final citable form. Please note that during the production process errors may be discovered which could affect the content, and all legal disclaimers that apply to the journal pertain.
}

CONFLICT OF INTEREST STATEMENT

The authors disclose that they have no conflict of interest. 
pattern of risk was observed for recent activity $\left(\mathrm{BMI}<25 \mathrm{~kg} / \mathrm{m}^{2}\right.$, trend $p=0.11 ; \mathrm{BMI} \geq 25 \mathrm{~kg} / \mathrm{m}^{2}$, trend $\mathrm{p}=0.16$; homogeneity-of-trends $p=0.04$ ). Associations for long-term activity did not appear to be driven by activity in any particular life period (e.g. youth, adulthood).

Conclusions-Long-term physical activity may reduce papillary thyroid cancer risk among normal weight and underweight women.

\section{Keywords}

Physical activity; thyroid cancer; cancer prevention; women; overweight/obesity; Body Mass Index

\section{INTRODUCTION}

Rates of thyroid cancer in US women $(18.5$ per 100,000) are three-fold greater than those in men $(5.9$ per 100,000$)$, and age-specific incidence patterns differ by sex ${ }^{1}$. Women's rates increase rapidly during adolescence and young adult years, and plateau around menopause ${ }^{2}$. Men's rates increase slowly and steadily throughout life until age 74 years then decline ${ }^{2}$. Papillary thyroid cancer, the most common subtype ${ }^{3}$, comprises approximately $86 \%$ of thyroid cancers in the US ${ }^{1}$ and has a median age of diagnosis of 46 years $^{4}$. Notably, ageadjusted incidence rates of papillary thyroid cancer have tripled among women and doubled among men between 1980 and $2005^{5}$. While improved imaging and diagnostic techniques probably account for some portion of the observed increase in incidence ${ }^{6,7}$, other factors are also likely involved; for example, it has been suggested that adiposity may be involved ${ }^{8}$, perhaps mirroring the US obesity epidemic.

Established risk factors for thyroid cancer include ionizing radiation (particularly exposures in infancy and childhood) $)^{7,9}$ and family history of proliferative thyroid disease ${ }^{10}$ (including goiter, benign nodules and adenomas ${ }^{7,10}$ ). Hyperthyroidism/hypothyroidism ${ }^{10-13}$, iodine deficiency (for follicular subtype $)^{14}$, and certain hormonal and reproductive factors have also been associated with increased risk ${ }^{7}, 15$. However, few studies have examined physical activity, which may affect thyroid cancer risk through DNA repair ${ }^{16-18}$, and hormonal ${ }^{19-21}$, metabolic ${ }^{21-23}$, and anti-inflammatory ${ }^{24,25}$ pathways.

While the relationship between physical activity and reduced risk of some cancers (e.g., breast cancer ${ }^{26-29}$ ) is well-established, its relationship with thyroid cancer has been minimally addressed. One study ${ }^{30}$ found that any strenuous "regular" recreational exercise in the two years before diagnosis or reference date was associated with a $24 \%$ reduced risk of papillary thyroid cancer. Other studies ${ }^{8,13,31-34}$ showed null results, but either the method of physical activity measurement was not described ${ }^{31,32}$, or physical activity was measured using instruments assessing only current activity ${ }^{33,34}$ or activity during the year prior to cohort enrollment ${ }^{8,13,34}$. Body size may also influence thyroid cancer risk ${ }^{35,36}$.

Although studies on physical activity and thyroid cancer risk have primarily measured current or recent activity ${ }^{8,13,32-34}$, activity performed earlier in life or throughout life may be a more important determinant of cancer risk. Only one study ${ }^{30}$ has examined the association between physical activity during adolescence and thyroid cancer risk; results showed a $17 \%$, statistically non-significant risk reduction among women reporting regular exercise between ages 12 and 21 years. No prospective cohort study has examined the association between long-term physical activity and thyroid cancer risk.

The hypothesis for this study was that long-term recreational physical activity is associated with decreased relative risk of papillary thyroid cancer among women participating in the 
California Teachers Study (CTS). The possible confounding or modifying effects of body mass index (BMI) were also examined.

\section{MATERIAL AND METHODS}

\section{Study population and data collection}

The CTS is a prospective cohort study of 133,479 women who were former or current public school professionals who were members of the California State Teachers Retirement System at recruitment in $1995^{37}$. Women completed a mailed baseline questionnaire which collected information on demographics; personal and family history of selected diseases and conditions (including some cancers); smoking; diet during the past year (measured by Block's food frequency questionnaire ${ }^{38}$ ); alcohol consumption in various life periods; menstrual and reproductive histories; use of hormones; height; weight; and recreational physical activity.

The CTS was approved by the institutional review board at the four participating centers (City of Hope, Cancer Prevention Institute of California, University of California at Irvine, and University of Southern California), in accord with assurances filed with and approved by the US Department of Health and Human Services.

The physical activity assessment provided examples of moderate activities (e.g. brisk walking and golf) and strenuous activities (e.g. swimming laps, running). Participants were asked to estimate for total moderate activities and for total strenuous activities how many hours per week (none, 1/2, 1, 1 1/2, 2, 3, 4-6, 7-10, and 11 or more hours per week) and months per year (1-3, 4-6, 7-9, and 10-12 months per year) they performed these activities during six time intervals (during high school; between the ages of 18-24, 25-34, 35-44 and 45-54 years; and during the past 3 years). Annual hours per week for each period were calculated separately for mean strenuous activity and mean moderate activity by multiplying the hours per week (using values of 5 hours, 8.5 hours, and 12 hours per week for the three upper activity categories) by the portion of the year in which the woman engaged in the activity. Approximate metabolic equivalent (MET) values from the compendium of energy costs of physical activities ${ }^{39}$ were assigned to moderate activities (4.5 METs) and strenuous activity (6.5 METs). Total MET-hours per week per year were calculated for each age period by multiplying the average hours per week per year in each category of activity (moderate or strenuous) by the appropriate MET value. Within each age period, this computed value was assigned to each year of age that the woman completed (e.g., for a 50 year-old woman, this value was assigned for the years from age 45 through age 50 years).

Long-term recreational physical activity was defined for this analysis as MET-hours per week of recreational physical activity from high school through age 54 years (or the participant's age at cohort entry if younger), and was calculated separately for moderate and strenuous activity by averaging the aforementioned period-specific MET hours per week per year values across all relevant age periods. Recent physical activity was defined as activity reported for the 3-year period prior to cohort entry and MET hours per week were assigned as described above. Measures of moderate and strenuous physical activity were also combined by summing the MET-hours per week per year values. MET-hours per week of combined moderate and strenuous activity were categorized as <5.5, 5.5-16.4, 16.5-32.9, and 33.0+ (approximate quartiles). Risk for $\geq 5.5$ MET-hours per week of combined moderate and strenuous activity compared to <5.5 MET-hours per week was considered a proxy for any vs. no activity. Finally, a 4-level summary variable describing combined moderate and strenuous activity (active vs. inactive) in both early adulthood (ages 18-24) and middle adulthood (ages 25-54) was examined. 
To define the eligible cohort, women were excluded in sequence if they: were non-residents of California at baseline $(\mathrm{n}=8,867,6.6 \%)$, limited participation to research on breast cancer $(n=18)$, reported a prior history of thyroid cancer at baseline $(n=557,0.4 \%)$ or had unknown history of cancer $(n=662,0.5 \%)$, had unreliable baseline questionnaire responses $(n=3)$, or were 80 years or older at baseline $(n=5,728,4.3 \%)$. Also excluded were women who did not complete the physical activity section on the baseline questionnaire $(n=665,0.5 \%)$, and women whose reported time spent in daily activities (casual walking, housework, standing or walking at work, sitting, and sleeping) was improbable $(n=40)$. Thus, 116,939 women comprised the analytic cohort.

\section{Assessment of thyroid cancer incidence}

Participants diagnosed with a first primary papillary thyroid cancer (ICD-O-3 site code C73.9 and histology codes 8050, 8260, 8340-8344, and 8350) after joining the cohort and before January 1, 2010 were identified through linkage with the California Cancer Registry (CCR), a legally-mandated statewide population-based cancer reporting system. CCR ascertainment of newly-diagnosed cancers is estimated to be $99 \%$ complete $^{40}$.

Follow-up began on the date the baseline questionnaire was completed (1995-1996) and ended with the first of the following: a thyroid cancer diagnosis ( $\mathrm{n}=309$ total), a permanent move outside of California ( $\mathrm{n}=10,822)$, death $(\mathrm{n}=10,512)$, or December 31, 2009 $(n=95,296)$. Residence was monitored through annual newsletter mailings or questionnaire mailings, annual linkages with the US Postal Service national change-of-address database, and notifications submitted by participants. A permanent move outside of California occurred when a woman left California for at least four months. The eligible cohort accrued $1,488,391$ person-years of follow-up for analysis; median follow-up time was 12.7 years. Analyses were restricted to papillary thyroid cancer $(n=275)$, the most common subtype, as few cases of other histologic subtypes $(n=34)$ were diagnosed and etiologies of subtypes vary. Women with non-papillary thyroid cancer, who moved out of California or died were censored on the dates these events occurred.

\section{Statistical analyses}

The hazard rate ratio (represented as the relative risk [RR] and corresponding 95\% confidence interval $[\mathrm{CI}]$ ) were estimated for associations between long-term and recent physical activity and papillary thyroid cancer risk by fitting multivariable Cox proportionalhazards regression models ${ }^{41}$. The time scale (in days) was defined from age at baseline to age at event, censoring or end of follow-up. All Cox models were stratified by age at baseline (in years) to adjust for calendar effects. Models were also a priori adjusted for race/ ethnicity (non-Hispanic White, Other). The $911(0.8 \%)$ women who declined to state their race/ethnicity were combined with women of other races/ethnicities.

Candidate covariates were selected based upon associations documented in the literature between variables and both physical activity and papillary thyroid cancer. Covariates (assessed at baseline) were evaluated individually as potential confounders using a stringent $5 \%$ change in the race/ethnicity-adjusted and age-stratified physical activity RR. Health history covariates included history of thyroid disease, family history of thyroid cancer, history of smoking at least 100 cigarettes, alcohol intake during the past year, and tertiles of daily energy intake (kcal). Menstruation variables included age at menarche and a variable combining cycle length and time elapsing before menstrual periods became regular (assessed as the age at which a girl could predict within a few days when her next period would start). Additional reproductive history covariates included any oral contraceptive use, time between last pregnancy and joining the cohort, and a combined variable for menopausal status and hormone therapy. Of these variables, only oral contraceptive use 
(ever, never, unknown) met the study definition of a confounder, and thus was the only other covariate included in the multivariable-adjusted models. Analyses examining separate effects of moderate activity and strenuous activity were mutually adjusted. BMI $(<25.0$, $25.0-29.9,30.0 \mathrm{~kg} / \mathrm{m}^{2}$ ) was treated as a potential mediating variable, and multivariableadjusted models were further adjusted for BMI to evaluate how much of the physical activity association, if any, could be attributed to BMI. All covariates and BMI were included in their categorical forms.

Tests for trend were conducted to examine the dose-response relationship between physical activity and papillary thyroid cancer risk by fitting ordinal values corresponding to each exposure category and determining whether or not the slope parameter differed from zero using the Wald test ${ }^{42}$. Analyses evaluating activity in early adulthood and middle adulthood were limited to women aged 54 years or older who had complete activity histories through age 54 .

BMI $\left(<25.0, \geq 25.0 \mathrm{~kg} / \mathrm{m}^{2}\right)$ was also examined as a potential effect modifier of any physical activity association by creating two physical activity variables, for women with BMI $<25.0$ $\mathrm{kg} / \mathrm{m}^{2}$ and for women with BMI $\geq 25.0 \mathrm{~kg} / \mathrm{m}^{2}$, each representing the 4 categories of physical activity (Table 2). Homogeneity-of-trends was tested using a likelihood ratio (LR) test in which a model that fit a single variable representing the trend across 4 categories of physical activity (and adjusting for BMI) was compared to a model (also adjusted for BMI) that fit the two BMI-specific physical activity trend variables.

All statistical significance levels ( $p$ values) reported are two-sided. $P$ values $₫$ ).05 were considered statistically significant and were not corrected for multiple testing. Statistical analyses were conducted using Stata/IC (version 11.0; StataCorp LP, College Station, TX).

\section{RESULTS}

Characteristics of women in the analytic cohort are shown in Table 1. The median age at diagnosis was 57.0 years. Non-Hispanic White women and women with any oral contraceptives tended to report higher levels of long-term physical activity.

Women whose long-term physical activity averaged at least 5.5 MET-hours per week per year of combined moderate and strenuous activity had a $23 \%$ lower risk of papillary thyroid cancer than women who averaged less activity (i.e. were "inactive"), but the confidence interval contained 1.0 (RR=0.77 95\% CI: 0.57, 1.04, Table 2). Inclusion of BMI in the model did not attenuate the risk estimate ( $R R=0.77,95 \%$ CI: $0.57,1.04)$. Similarly, no association was observed between recent physical activity (activity during the three years before baseline) and papillary thyroid cancer.

BMI modified the association between long-term combined moderate and strenuous physical activity and papillary thyroid cancer risk (homogeneity-of-trends across BMI categories $p=0.03$; Table 3 ). Risk declined with increasing long-term activity among women with BMI under $25.0 \mathrm{~kg} / \mathrm{m}^{2}$ (i.e. normal weight or underweight women). Among these women, those performing 33.0+ MET-hours/week of long-term moderate and strenuous activity experienced a lower risk of papillary thyroid cancer (RR=0.63, 95\% CI: $0.39,1.02$ ) than those performing less than 5.5 MET-hours/week (trend $p=0.03$ ). A similar pattern was not observed among overweight or obese women. When examining moderate and strenuous long-term activity separately, the greater protection associated with higher levels of combined activity was not driven by strenuous activity (trend $p=0.34$ ) but by moderate activity (trend $p=0.06$ ). Further analyses revealed that physical activity in early adulthood conferred risk reductions similar to activity in middle adulthood (data not shown). 
Examining recent physical activity, BMI also modified the association between combined moderate and strenuous activity and papillary thyroid cancer risk (homogeneity-of-trends $p=0.04$; Table 3). For normal and underweight women (BMI $\left.<25.0 \mathrm{~kg} / \mathrm{m}^{2}\right)$, higher levels of recent physical activity were associated with lower risk, but for overweight or obese women, the trend was reversed; however, neither test for trend was statistically significant (trend $p=0.11$ and 0.16 , respectively).

\section{DISCUSSION}

This study found no association between physical activity and risk of papillary thyroid cancer overall, but results suggest that physical activity is associated with a decreased risk among normal weight or underweight women, particularly among those who averaged at least 16.5 MET-hours per week per year of activity from high school through age 54 years who experienced approximately a $40 \%$ risk reduction. No such association was observed for overweight or obese women (BMI $\geq 25.0 \mathrm{~kg} / \mathrm{m}^{2}$ ).

$\mathrm{Two}^{8,32}$ of the five ${ }^{8,13,30,32,33}$ prior studies of physical activity and thyroid cancer did not provide specific results for papillary thyroid cancer among women, and no studies have examined the role of long-term physical activity in thyroid cancer risk. Kolonel et al. ${ }^{32}$ observed no statistically significant association between thyroid cancer risk and heavy occupational physical activity in women $(\mathrm{OR}=0.9,95 \% \mathrm{CI}$ : $0.6,1.5)$, but neither the time period that was assessed, nor the duration of activity, was described. Similarly, Meinhold et al. ${ }^{13}$, Leitzmann et al. ${ }^{8}$, and Kabat et al. ${ }^{33}$ found no association in their prospective studies. Meinhold et al. ${ }^{13}$ reported a relative risk (RR) of 0.81 (95\% CI: $\left.0.51,1.29\right)$ among women for one hour or more of strenuous activity per week in the year prior to enrollment, and noted that restriction to papillary subtype did not markedly change their findings. Leitzmann et al. ${ }^{8}$ reported a RR for papillary thyroid cancer of 0.89 (95\% CI: $\left.0.59,1.36\right)$ among men and women combined for 20 minutes or more of vigorous activity, five times per week within the year prior to enrollment, but did not present RRs for women separately. Both of these studies only examined recent activity, within the year before cohort enrollment. While Kabat et al. ${ }^{33}$ examined physical activity prospectively, the "usual" pattern of activity rather than long-term activity was assessed, and their study was restricted to postmenopausal women whose mean age at diagnosis was nearly 62 years, whereas the median age at diagnosis in the present study was 57 years. In the only study to evaluate papillary-specific results in women and report a significant association, regular (at least 24 times per year) strenuous recreational exercise in the two years prior to the diagnosis or reference date was associated with a $24 \%$ reduction in the odds of papillary thyroid cancer (odds ratio $=0.76$, $95 \% \mathrm{CI}=0.59,0.98)$ with similar results for activity between the ages of 12 and 21 years; however, no dose-response relationship was observed ${ }^{30}$.

A pooled analysis ${ }^{34}$, the largest study of physical activity and thyroid cancer risk to date, used data from five cohorts (including two aforementioned cohorts ${ }^{8,13}$ ). Investigators reported no association between physical activity and thyroid cancer; however, all five cohorts assessed only current or recent activity characterized by study-specific tertiles (low, medium, high). Three of these cohorts assessed only vigorous/strenuous activity, and although results were presented for women and by papillary subtype, results specific to women with papillary subtype were not provided. The results from the current study showed that combined moderate and strenuous physical activity were associated with reduced risk of papillary thyroid cancer among women, but that these findings were limited to those women who were normal weight or underweight; the lack of a significant association among overweight and obese women or in the pooled analysis may be explained by the broader study population and choice of physical activity measurement (e.g. an emphasis on recent, strenuous activity). 
The current study examined both long-term and recent recreational physical activity, and provides some evidence for an association with lower papillary thyroid cancer risk among normal weight and underweight women, unlike prior cohort studies $8,13,33$ which showed little or no association. The magnitude of risk reduction found in this study for long-term combined moderate and strenuous physical activity among normal weight and underweight women was approximately $40 \%$ for an average of at least 16.5 MET-hours per week of activity from high school through age 54 years; this is slightly larger than risk reductions previously observed $^{8,13}, 30,32,33$. While Leitzmann et al. ${ }^{8}$ presented the effects of physical activity separately by BMI group $\left(<25.0,25.0-29.9,330.0 \mathrm{~kg} / \mathrm{m}^{2}\right)$, the analysis combined men and women and, for their measure of recent activity, no trend across activity levels was observed within any BMI group.

Several pathways may underlie an association between physical activity and thyroid cancer risk, including DNA repair, and anti-inflammatory and hormonal mechanisms. DNA damage, in particular single and double strand breaks ${ }^{43}$, has been associated with thyroid cancer risk ${ }^{17}$, and moderate physical activity may protect against DNA damage and increase DNA repair ${ }^{16-18}$, likely through increased telomerase action and reduced telomere shortening ${ }^{44}$. Physical activity is also associated with elevated levels of adiponectin, an antiinflammatory factor ${ }^{21,45}$ which may be associated with decreased risk of thyroid cancer ${ }^{46}$. However, these potential mechanisms may not explain why the association between physical activity and thyroid cancer risk was restricted to normal- or underweight women.

A hormonal hypothesis may also shed light on the results. Long-term physical activity appears to reduce levels of circulating, biologically available sex hormones (e.g. estrogens, androgens) ${ }^{19}$ which drive cell proliferation and increase the chances of random genetic mutations ${ }^{20}$, in turn reducing the risk of cancer. Physical activity may also increase amounts of circulating sex-hormone binding globulin, thereby reducing the availability of hormones, such as estradiol, to influence target tissues ${ }^{19,47}$ and reducing proliferation of thyroid cancer cells ${ }^{48}$. Decreased levels of female hormones may also lower levels of thyroid stimulating hormone (TSH) which is associated with thyroid hyperplasia and possibly cancer ${ }^{7}$. Thus, the aforementioned mechanisms, independently and combined, could lead to a decreased risk of thyroid cancer, which has been proposed as a hormone-related cancer ${ }^{20,49}$. The lack of any association among overweight or obese women is puzzling; issues of measurement error may be greater among these women, however the direction may be unclear. It is possible that overweight and obese women over-report their activities; however, it is also possible that, for each activity, overweight and obese women expend more energy simply by carrying extra weight during exercise and the MET scores under-represent their overall energy expenditure.

The present study has several limitations. Physical activity, BMI (previously validated ${ }^{50}$ ), and covariates were self-reported, and are thus subject to reporting error. The mean age at cohort entry was 51.9 years (standard deviation 13.1 years), so the recall period for activity at earlier ages (e.g. 18-24 years) would be greater for older women. Validity for the physical activity measure is not available given that no historical data for these women exist for comparison. Nonetheless, because this is a prospective cohort study, any errors in reporting would likely be non-differential between women who later developed papillary thyroid cancer and those who did not, but could theoretically differ based on personal characteristics (e.g. weight). Non-differential reporting errors would bias the relative risk estimates toward the null value. Previous results have shown that the activity measures used in this study confirm expected associations of long-term physical activity and decreased risk of breast $\mathrm{t}^{28}$ and colon cancer ${ }^{51}$. This study did not assess occupational or household physical activity, which could be important determinants of total energy expenditure ${ }^{28,52}$ that may affect thyroid cancer risk. 
The majority of women in the study are non-Hispanic White, thus precluding determination of risk variation by race or ethnicity. In addition, education and income were not assessed on the baseline survey, but education levels should be similar (all women would be expected to have college degrees) and even if income levels differed, socioeconomic status (as measured from follow-up surveys and by census data related to residential address at baseline) was not a confounder in similar CTS studies of physical activity. Due to the relatively low number of cases, analyses were not performed separately within various age groups; however, all comparisons are among women of the same age, as age was used as the time scale.

Additionally, there was no evidence that the proportional-hazards assumption was violated.

Despite its limitations, this is the first cohort study to assess long-term physical activity and thyroid cancer risk. By collecting information on physical activity at baseline (prior to diagnosis), differential recall by disease status, as is often present in case-control studies, is minimized.

In summary, the present study found that although the overall association between physical activity and papillary thyroid cancer risk was not significant, for women with a BMI under $25.0 \mathrm{~kg} / \mathrm{m}^{2}$, long-term recreational combined moderate and strenuous physical activity averaging at least 16.5 MET-hours per week was associated with reduced risk of papillary thyroid cancer.

\section{Acknowledgments}

The work reported here was supported by National Cancer Institute grants R01 CA77398, K05 CA 136967, and R03 CA125819 and contract 97-10500 from the California Breast Cancer Research Fund. The funding sources did not contribute to the design or conduct of the study, nor to the writing or submission of this manuscript. The collection of cancer incidence data used in this study was supported by the California Department of Health Services as part of the statewide cancer reporting program mandated by California Health and Safety Code Section 103885; the National Cancer Institute's Surveillance, Epidemiology and End Results Program under contract N01PC-35136 awarded to the Cancer Prevention Institute of California, contract N01-PC-35139 awarded to the University of Southern California, and contract N02-PC-15105 awarded to the Public Health Institute; and the Centers for Disease Control and Prevention's National Program of Cancer Registries, under agreement \#U55/ CCR921930-02 awarded to the Public Health Institute. The ideas and opinions expressed herein are those of the authors. Endorsement by the State of California, Department of Health Services, the National Cancer Institute, and the Centers for Disease Control and Prevention or their contractors and subcontractors is not intended nor should be inferred.

The authors would like to thank CTS Steering Committee members who did not directly contribute to the current paper but participate on the study's Steering Committee: Hoda Anton-Culver, Christina A. Clarke, Dennis Deapen, Katherine D. Henderson, James V. Lacey Jr, David O. Nelson, Susan L. Neuhausen, Richard Pinder, Fredrick Schumacher, Sophia S. Wang, and Argyrios Ziogas.

\section{REFERENCES}

1. Altekruse, SF.; Kosary, CL.; Krapcho, M.; Neyman, N.; Aminou, R.; Waldron, W.; Ruhl, J.; Howlader, N.; Tatalovich, Z.; Cho, H.; Mariotto, A.; Eisner, M,P., et al. SEER Cancer Statistics Review, 1975-2007. National Cancer Institute; Bethesda, MD: 2010. SEER: Thyroid Cancer.

2. Hodgson NC, Button J, Solorzano CC. Thyroid cancer: is the incidence still increasing? Ann Surg Oncol. 2004; 11(12):1093-7. [PubMed: 15576834]

3. Kilfoy BA, Zheng T, Holford TR, Han X, Ward MH, Sjodin A, Zhang Y, Bai Y, Zhu C, Guo GL, Rothman N. International patterns and trends in thyroid cancer incidence, 1973-2002. Cancer Causes Control. 2009; 20(5):525-31. [PubMed: 19016336]

4. Albores-Saavedra J, Henson DE, Glazer E, Schwartz AM. Changing patterns in the incidence and survival of thyroid cancer with follicular phenotype--papillary, follicular, and anaplastic: a morphological and epidemiological study. Endocr Pathol. 2007; 18(1):1-7. [PubMed: 17652794] 
5. Enewold L, Zhu K, Ron E, Marrogi AJ, Stojadinovic A, Peoples GE, Devesa SS. Rising thyroid cancer incidence in the United States by demographic and tumor characteristics, 1980-2005. Cancer Epidemiol Biomarkers Prev. 2009; 18(3):784-91. [PubMed: 19240234]

6. Verkooijen HM, Fioretta G, Pache JC, Franceschi S, Raymond L, Schubert H, Bouchardy C. Diagnostic changes as a reason for the increase in papillary thyroid cancer incidence in Geneva, Switzerland. Cancer Causes Control. 2003; 14(1):13-7. [PubMed: 12708720]

7. Dal Maso L, Bosetti C, La Vecchia C, Franceschi S. Risk factors for thyroid cancer: an epidemiological review focused on nutritional factors. Cancer Causes Control. 2009; 20(1):75-86. [PubMed: 18766448]

8. Leitzmann MF, Brenner A, Moore SC, Koebnick C, Park Y, Hollenbeck A, Schatzkin A, Ron E. Prospective study of body mass index, physical activity and thyroid cancer. Int J Cancer. 2010; 126(12):2947-56. [PubMed: 19795465]

9. Schottenfeld D. Epidemiology of thyroid cancer. Laryngoscope. 1978; 88(1 Pt 2 Suppl 8):55-7. [PubMed: 619211]

10. Horn-Ross PL, Morris JS, Lee M, West DW, Whittemore AS, McDougall IR, Nowels K, Stewart SL, Spate VL, Shiau AC, Krone MR. Iodine and thyroid cancer risk among women in a multiethnic population: the Bay Area Thyroid Cancer Study. Cancer Epidemiol Biomarkers Prev. 2001; 10(9):979-85. [PubMed: 11535551]

11. Franceschi S, Preston-Martin S, Dal Maso L, Negri E, La Vecchia C, Mack WJ, McTiernan A, Kolonel L, Mark SD, Mabuchi K, Jin F, Wingren G, et al. A pooled analysis of case-control studies of thyroid cancer. IV. Benign thyroid diseases. Cancer Causes Control. 1999; 10(6):58395. [PubMed: 10616827]

12. Iribarren C, Haselkorn T, Tekawa IS, Friedman GD. Cohort study of thyroid cancer in a San Francisco Bay area population. Int J Cancer. 2001; 93(5):745-50. [PubMed: 11477590]

13. Meinhold CL, Ron E, Schonfeld SJ, Alexander BH, Freedman DM, Linet MS, Berrington de Gonzalez A. Nonradiation risk factors for thyroid cancer in the US Radiologic Technologists Study. Am J Epidemiol. 2009; 171(2):242-52. [PubMed: 19951937]

14. Belfiore A, La Rosa GL, La Porta GA, Giuffrida D, Milazzo G, Lupo L, Regalbuto C, Vigneri R. Cancer risk in patients with cold thyroid nodules: relevance of iodine intake, sex, age, and multinodularity. Am J Med. 1992; 93(4):363-9. [PubMed: 1415299]

15. Horn-Ross P, Canchola A, Ma H, Reynolds P, Bernstein L. Hormonal factors and the risk of papillary thyroid cancer in the California Teachers Study cohort. Cancer Epidemiol Biomarkers Prev. in press; in press.

16. Radak Z, Kaneko T, Tahara S, Nakamoto H, Ohno H, Sasvari M, Nyakas C, Goto S. The effect of exercise training on oxidative damage of lipids, proteins, and DNA in rat skeletal muscle: evidence for beneficial outcomes. Free Radic Biol Med. 1999; 27(1-2):69-74. [PubMed: 10443921]

17. Alessio HM. Exercise-induced oxidative stress. Med Sci Sports Exerc. 1993; 25(2):218-24. [PubMed: 8383786]

18. Schneider S, Willis PE, Parkhouse WS. The effects of age and physical activity on cardiac mitochondrial DNA template availability. Age. 1995; 18(4):151-157.

19. Friedenreich CM, Orenstein MR. Physical activity and cancer prevention: etiologic evidence and biological mechanisms. J Nutr. 2002; 132(11 Suppl):3456S-3464S. [PubMed: 12421870]

20. Henderson BE, Feigelson HS. Hormonal carcinogenesis. Carcinogenesis. 2000; 21(3):427-33. [PubMed: 10688862]

21. McTiernan A. Mechanisms linking physical activity with cancer. Nat Rev Cancer. 2008; 8(3):20511. [PubMed: 18235448]

22. Samani AA, Yakar S, LeRoith D, Brodt P. The role of the IGF system in cancer growth and metastasis: overview and recent insights. Endocr Rev. 2007; 28(1):20-47. [PubMed: 16931767]

23. Vella V, Sciacca L, Pandini G, Mineo R, Squatrito S, Vigneri R, Belfiore A. The IGF system in thyroid cancer: new concepts. Mol Pathol. 2001; 54(3):121-4. [PubMed: 11376121]

24. Russell JP, Shinohara S, Melillo RM, Castellone MD, Santoro M, Rothstein JL. Tyrosine kinase oncoprotein, RET/PTC3, induces the secretion of myeloid growth and chemotactic factors. Oncogene. 2003; 22(29):4569-77. [PubMed: 12881713] 
25. Russell JP, Engiles JB, Rothstein JL. Proinflammatory mediators and genetic background in oncogene mediated tumor progression. J Immunol. 2004; 172(7):4059-67. [PubMed: 15034017]

26. Monninkhof EM, Elias SG, Vlems FA, van der Tweel I, Schuit AJ, Voskuil DW, van Leeuwen FE. Physical activity and breast cancer: a systematic review. Epidemiology. 2007; 18(1):137-57. [PubMed: 17130685]

27. Bernstein L, Henderson BE, Hanisch R, Sullivan-Halley J, Ross RK. Physical exercise and reduced risk of breast cancer in young women. J Natl Cancer Inst. 1994; 86(18):1403-8. [PubMed: 8072034]

28. Dallal CM, Sullivan-Halley J, Ross RK, Wang Y, Deapen D, Horn-Ross PL, Reynolds P, Stram DO, Clarke CA, Anton-Culver H, Ziogas A, Peel D, et al. Long-term recreational physical activity and risk of invasive and in situ breast cancer: the California teachers study. Arch Intern Med. 2007; 167(4):408-15. [PubMed: 17325304]

29. Sprague BL, Trentham-Dietz A, Newcomb PA, Titus-Ernstoff L, Hampton JM, Egan KM. Lifetime recreational and occupational physical activity and risk of in situ and invasive breast cancer. Cancer Epidemiol Biomarkers Prev. 2007; 16(2):236-43. [PubMed: 17301255]

30. Rossing MA, Remler R, Voigt LF, Wicklund KG, Daling JR. Recreational physical activity and risk of papillary thyroid cancer (United States). Cancer Causes Control. 2001; 12(10):881-5. [PubMed: 11808706]

31. Suzuki T, Matsuo K, Hasegawa Y, Hiraki A, Kawase T, Tanaka H, Tajima K. Anthropometric factors at age 20 years and risk of thyroid cancer. Cancer Causes Control. 2008; 19(10):1233-42. [PubMed: 18618280]

32. Kolonel LN, Hankin JH, Wilkens LR, Fukunaga FH, Hinds MW. An epidemiologic study of thyroid cancer in Hawaii. Cancer Causes Control. 1990; 1(3):223-34. [PubMed: 2102295]

33. Kabat GC, Kim MY, Thomson CA, Luo J, Wactawski-Wende J, Rohan TE. Anthropometric factors and physical activity and risk of thyroid cancer in postmenopausal women. Cancer Causes Control. 2012; 23(3):421-30. [PubMed: 22212611]

34. Kitahara CM, Platz EA, Beane Freeman LE, Black A, Hsing AW, Linet MS, Park Y, Schairer C, Berrington de Gonzalez A. Physical activity, diabetes, and thyroid cancer risk: a pooled analysis of five prospective studies. Cancer Causes Control. 2012

35. Ron E, Kleinerman RA, Boice JD Jr. LiVolsi VA, Flannery JT, Fraumeni JF Jr. A populationbased case-control study of thyroid cancer. J Natl Cancer Inst. 1987; 79(1):1-12. [PubMed: 3474436]

36. Ron E, Lubin JH, Shore RE, Mabuchi K, Modan B, Pottern LM, Schneider AB, Tucker MA, Boice JD Jr. Thyroid cancer after exposure to external radiation: a pooled analysis of seven studies. Radiat Res. 1995; 141(3):259-77. [PubMed: 7871153]

37. Bernstein L, Allen M, Anton-Culver H, Deapen D, Horn-Ross PL, Peel D, Pinder R, Reynolds P, Sullivan-Halley J, West D, Wright W, Ziogas A, et al. High breast cancer incidence rates among California teachers: results from the California Teachers Study (United States). Cancer Causes Control. 2002; 13(7):625-35. [PubMed: 12296510]

38. Horn-Ross PL, Lee VS, Collins CN, Stewart SL, Canchola AJ, Lee MM, Reynolds P, Clarke CA, Bernstein L, Stram DO. Dietary assessment in the California Teachers Study: reproducibility and validity. Cancer Causes Control. 2008; 19(6):595-603. [PubMed: 18256894]

39. Ainsworth BE, Haskell WL, Whitt MC, Irwin ML, Swartz AM, Strath SJ, O’Brien WL, Bassett DR Jr. Schmitz KH, Emplaincourt PO, Jacobs DR Jr. Leon AS. Compendium of physical activities: an update of activity codes and MET intensities. Med Sci Sports Exerc. 2000; 32(9 Suppl):S498-504. [PubMed: 10993420]

40. Kwong, SL.; Perkins, CI.; Morris, CR.; Cohen, R.; Allen, M.; Wright, WE. Cancer in California: 1988-1999. Department of Health Services, Cancer Surveillance Section; Sacramento, CA: 2001.

41. Cox, D.; Oakes, D. Analysis of survival data. Chapman \& Hall; London, England: 1984.

42. Rothman, KJ.; Greenland, S. Modern Epidemiology. Lippincott-Raven; Philadelphia: 1998.

43. Sigurdson AJ, Hauptmann M, Alexander BH, Doody MM, Thomas CB, Struewing JP, Jones IM. DNA damage among thyroid cancer and multiple cancer cases, controls, and long-lived individuals. Mutat Res. 2005; 586(2):173-88. [PubMed: 16099702] 
44. Ludlow AT, Zimmerman JB, Witkowski S, Hearn JW, Hatfield BD, Roth SM. Relationship between physical activity level, telomere length, and telomerase activity. Med Sci Sports Exerc. 2008; 40(10):1764-71. [PubMed: 18799986]

45. Esposito K, Pontillo A, Di Palo C, Giugliano G, Masella M, Marfella R, Giugliano D. Effect of weight loss and lifestyle changes on vascular inflammatory markers in obese women: a randomized trial. JAMA. 2003; 289(14):1799-804. [PubMed: 12684358]

46. Roberts DL, Dive C, Renehan AG. Biological mechanisms linking obesity and cancer risk: new perspectives. Annu Rev Med. 2010; 61:301-16. [PubMed: 19824817]

47. McTiernan A, Wu L, Chen C, Chlebowski R, Mossavar-Rahmani Y, Modugno F, Perri MG, Stanczyk FZ, Van Horn L, Wang CY. Relation of BMI and physical activity to sex hormones in postmenopausal women. Obesity. 2006; 14(9):1662-77. [PubMed: 17030978]

48. Vivacqua A, Bonofiglio D, Albanito L, Madeo A, Rago V, Carpino A, Musti AM, Picard D, Ando S, Maggiolini M. 17 beta-estradiol, genistein, and 4-hydroxytamoxifen induce the proliferation of thyroid cancer cells through the g protein-coupled receptor GPR30. Mol Pharmacol. 2006; 70(4): 1414-23. [PubMed: 16835357]

49. Henderson BE, Ross RK, Pike MC, Casagrande JT. Endogenous hormones as a major factor in human cancer. Cancer Res. 1982; 42(8):3232-9. [PubMed: 7046921]

50. Canchola AJ, Chang ET, Bernstein L, Largent JA, Reynolds P, Deapen D, Ursin G, Horn-Ross PL. Body size and the risk of endometrial cancer by hormone therapy use in postmenopausal women in the California Teachers Study cohort. Cancer Causes Control. 2010; 21(9):1407-16. [PubMed: 20431936]

51. Mai PL, Sullivan-Halley J, Ursin G, Stram DO, Deapen D, Villaluna D, Horn-Ross PL, Clarke CA, Reynolds P, Ross RK, West DW, Anton-Culver H, et al. Physical activity and colon cancer risk among women in the California Teachers Study. Cancer Epidemiol Biomarkers Prev. 2007; 16(3): 517-25. [PubMed: 17372247]

52. Verloop J, Rookus MA, van der Kooy K, van Leeuwen FE. Physical activity and breast cancer risk in women aged 20-54 years. J Natl Cancer Inst. 2000; 92(2):128-35. [PubMed: 10639514] 


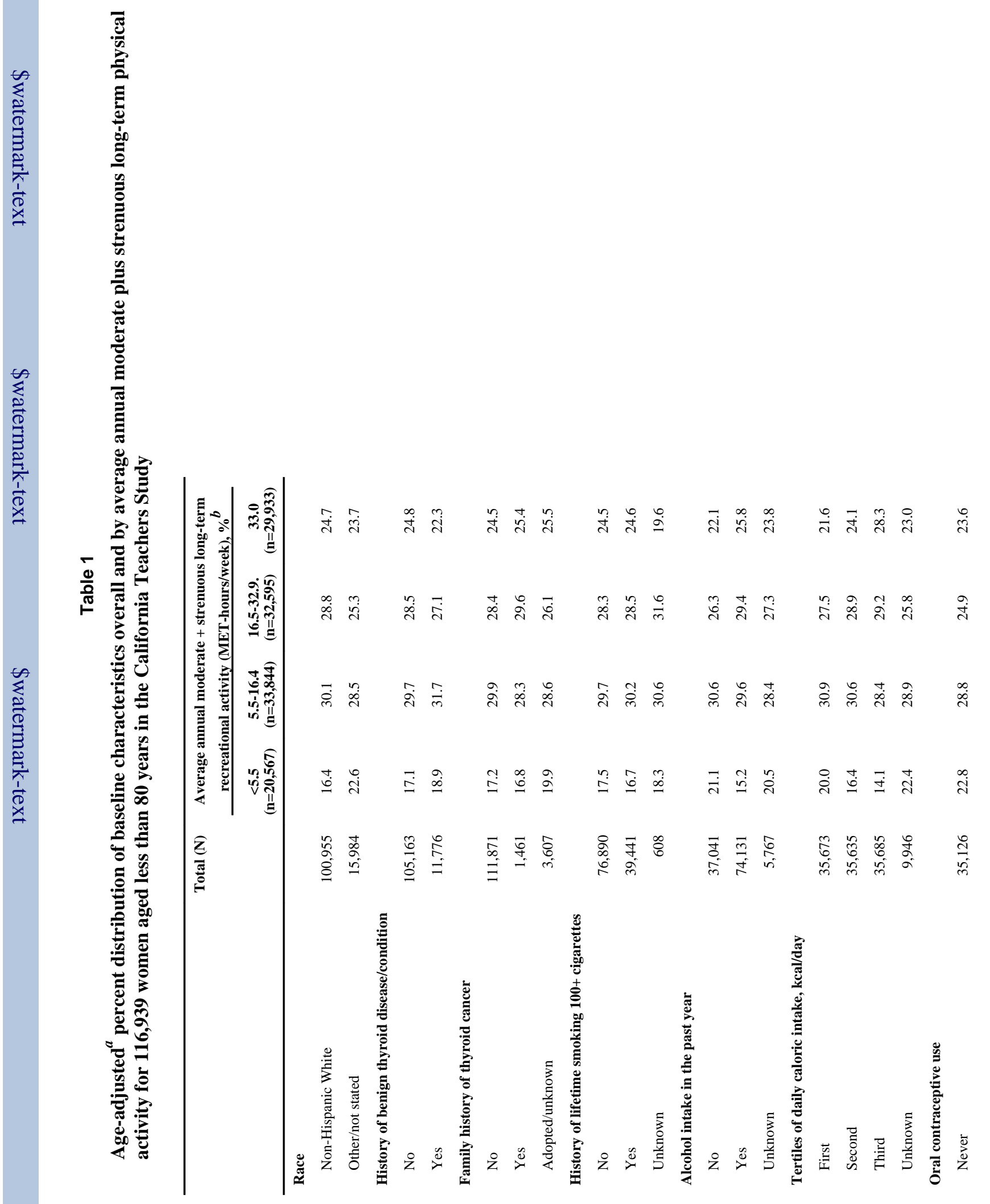




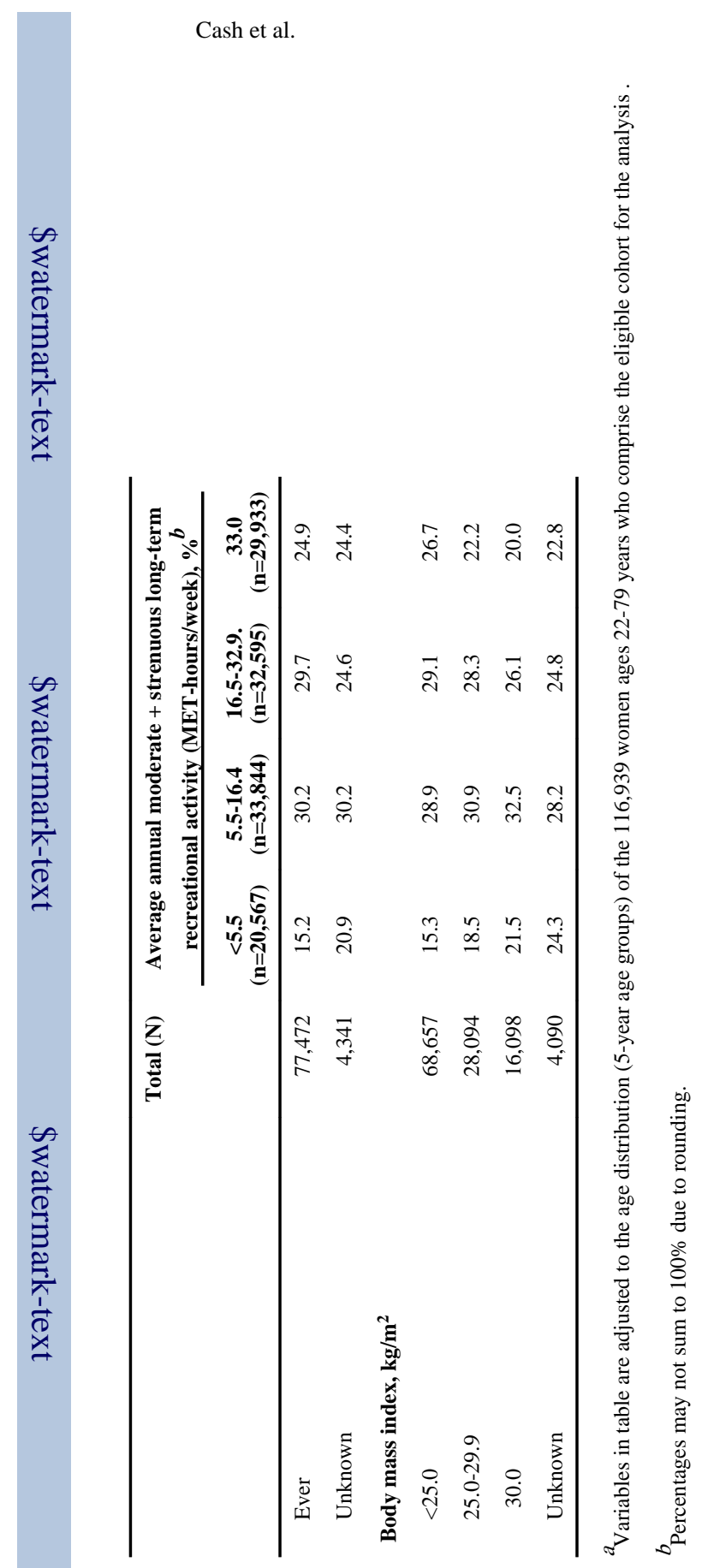

Page 13 
Table 2

Relative risks for the association between long-term and recent physical activity and papillary thyroid cancer in 116,939 women under 80 years of age in the California Teachers Study

\begin{tabular}{|c|c|c|c|c|}
\hline & \multirow[t]{2}{*}{$\begin{array}{l}\text { Observed } \\
\text { person-years }\end{array}$} & \multirow[t]{2}{*}{ No. cases } & \multicolumn{2}{|c|}{ Adjusted relative risk $^{a}$ (95\% confidence interval) } \\
\hline & & & Multivariable-adjusted $^{a}$ & $\begin{array}{l}\text { Multivariable- and BMI- }{ }^{a, b} \\
\text { adjusted }\end{array}$ \\
\hline \multicolumn{5}{|c|}{$\begin{array}{l}\text { AVERAGE ANNUAL MODERATE } \\
\text { PHYSICAL ACTIVITY }\end{array}$} \\
\hline \multicolumn{5}{|c|}{ (MET-hours/week) $^{c}$} \\
\hline \multicolumn{5}{|l|}{ Long-term } \\
\hline$<5.5$ & 294,078 & 59 & Reference & Reference \\
\hline 25.5 & $1,194,313$ & 216 & $0.83(0.61-1.12)$ & $0.82(0.61-1.12)$ \\
\hline $5.5-16.4$ & 377,549 & 70 & $0.85(0.60-1.21)$ & $0.85(0.59-1.21)$ \\
\hline $16.5-32.9$ & 387,847 & 71 & $0.84(0.59-1.21)$ & $0.84(0.58-1.20)$ \\
\hline $33.0+$ & 428,917 & 75 & $0.80(0.55-1.17)$ & $0.80(0.55-1.16)$ \\
\hline Trend $p$ & & & 0.29 & 0.28 \\
\hline \multicolumn{5}{|l|}{ Past 3 years } \\
\hline$<5.5$ & 382,983 & 75 & Reference & Reference \\
\hline 25.5 & $1,105,408$ & 200 & $0.90(0.68-1.18)$ & $0.89(0.67-1.18)$ \\
\hline $5.5-16.4$ & 310,186 & 61 & $0.98(0.70-1.39)$ & $0.98(0.69-1.39)$ \\
\hline $16.5-32.9$ & 307,855 & 53 & $0.85(0.59-1.22)$ & $0.84(0.58-1.22)$ \\
\hline $33.0+$ & 487,367 & 86 & $0.87(0.62-1.21)$ & $0.87(0.62-1.21)$ \\
\hline Trend $p$ & & & 0.32 & 0.32 \\
\hline \multicolumn{5}{|c|}{$\begin{array}{l}\text { AVERAGE ANNUAL STRENOUS } \\
\text { PHYSICAL ACTIVITY }\end{array}$} \\
\hline \multicolumn{5}{|c|}{ (MET-hours/week) $^{c}$} \\
\hline \multicolumn{5}{|l|}{ Long-term } \\
\hline$<5.5$ & 424,329 & 73 & Reference & Reference \\
\hline 25.5 & $1,064,062$ & 202 & $1.03(0.77-1.37)$ & $1.03(0.77-1.37)$ \\
\hline $5.5-16.4$ & 355,292 & 71 & $1.10(0.79-1.54)$ & $1.10(0.78-1.54)$ \\
\hline $16.5-32.9$ & 329,012 & 56 & $0.91(0.63-1.32)$ & $0.91(0.63-1.32)$ \\
\hline $33.0+$ & 379,757 & 75 & $1.08(0.75-1.56)$ & $1.08(0.75-1.57)$ \\
\hline Trend $p$ & & & 0.91 & 0.90 \\
\hline \multicolumn{5}{|l|}{ Past 3 years } \\
\hline$<5.5$ & 753,141 & 132 & Reference & Reference \\
\hline 25.5 & 735,250 & 143 & $1.07(0.83-1.38)$ & $1.07(0.83-1.38)$ \\
\hline $5.5-16.4$ & 231,147 & 41 & $0.97(0.67-1.39)$ & $0.97(0.67-1.39)$ \\
\hline $16.5-32.9$ & 188,237 & 33 & $0.98(0.66-1.45)$ & $0.98(0.66-1.46)$ \\
\hline $33.0+$ & 315,866 & 69 & $1.24(0.90-1.70)$ & $1.25(0.91-1.72)$ \\
\hline Trend $p$ & & & 0.24 & 0.23 \\
\hline $\begin{array}{l}\text { AVERAGE } \\
\text { +STRENUO } \\
\text { (MET-hours }\end{array}$ & & & & \\
\hline
\end{tabular}




\begin{tabular}{|c|c|c|c|c|}
\hline & \multirow[t]{2}{*}{$\begin{array}{c}\text { Observed } \\
\text { person-years }\end{array}$} & \multirow[t]{2}{*}{ No. cases } & \multicolumn{2}{|c|}{ Adjusted relative risk $^{a}$ (95\% confidence interval) } \\
\hline & & & Multivariable-adjusted $^{a}$ & $\begin{array}{c}\text { Multivariable- and BMI- } \\
\text { adjusted }\end{array}$ \\
\hline \multicolumn{5}{|l|}{ Long-term } \\
\hline$<5.5$ & 256,838 & 53 & Reference & Reference \\
\hline 25.5 & $1,231,553$ & 222 & $0.77(0.57-1.04)$ & $0.77(0.57-1.04)$ \\
\hline $5.5-16.4$ & 431,698 & 77 & $0.78(0.55-1.11)$ & $0.78(0.55-1.11)$ \\
\hline $16.5-32.9$ & 417,536 & 76 & $0.76(0.53-1.09)$ & $0.76(0.53-1.09)$ \\
\hline $33.0+$ & 382,318 & 69 & $0.76(0.53-1.10)$ & $0.76(0.53-1.10)$ \\
\hline Trend $p$ & & & 0.21 & 0.21 \\
\hline \multicolumn{5}{|l|}{ Past 3 years } \\
\hline$<5.5$ & 453,222 & 86 & Reference & Reference \\
\hline 25.5 & $1,035,169$ & 189 & $0.94(0.73-1.22)$ & $0.94(0.73-1.23)$ \\
\hline $5.5-16.4$ & 394,207 & 76 & $0.99(0.73-1.36)$ & $0.99(0.73-1.35)$ \\
\hline $16.5-32.9$ & 330,304 & 54 & $0.84(0.60-1.19)$ & $0.84(0.60-1.19)$ \\
\hline $33.0+$ & 310,658 & 59 & $0.99(0.71-1.38)$ & $0.99(0.71-1.39)$ \\
\hline Trend $p$ & & & 0.67 & 0.70 \\
\hline
\end{tabular}

BMI: Body Mass Index

${ }^{a}$ Stratified by age (years) and adjusted for categories of race (non-Hispanic White, Other/unknown) and oral contraceptive use (ever, never, unknown).

${ }^{b}$ Additionally adjusted for BMI $\left(<25,25-29.9, \geq 30 \mathrm{~kg} / \mathrm{m}^{2}\right.$, unknown).

${ }^{c}$ Moderate physical activity and strenuous physical activity mutually adjusted for each other. 
Table 3

Relative risks for the association between physical activity and papillary thyroid cancer in 112,849 women aged less than 80 years with BMI reported in the California Teachers Study

\begin{tabular}{|c|c|c|c|c|}
\hline & \multicolumn{2}{|l|}{ No. cases } & \multicolumn{2}{|c|}{$\begin{array}{l}\text { Adjusted relative risk ( } 95 \% \\
\text { Confidence Interval) }\end{array}$} \\
\hline & $\mathrm{BMI}<25 \mathrm{~kg} / \mathrm{m}^{2}$ & $\mathrm{BMI} \geq 25 \mathrm{~kg} / \mathrm{m}^{2}$ & BMI $<25 \mathrm{~kg} / \mathrm{m}^{2}$ & BMI $\geq 25 \mathrm{~kg} / \mathrm{m}^{2}$ \\
\hline \multicolumn{5}{|c|}{$\begin{array}{l}\text { AVERAGE ANNUAL MODERATE } \\
\text { PHYSICAL ACTIVITY }\end{array}$} \\
\hline \multicolumn{5}{|l|}{ Long-term } \\
\hline$<5.5$ & 37 & 21 & Reference & Reference \\
\hline $5.5-16.4$ & 40 & 28 & $0.76(0.48-1.19)$ & $0.97(0.55-1.72)$ \\
\hline $16.5-32.9$ & 43 & 26 & $0.75(0.48-1.18)$ & $0.93(0.52-1.68)$ \\
\hline $33.0+$ & 41 & 33 & $0.62(0.39-0.99)$ & $1.13(0.64-1.99)$ \\
\hline Trend $p$ & & & 0.06 & 0.69 \\
\hline Homogeneity-of-trends $p$ & & & 0.12 & \\
\hline \multicolumn{5}{|l|}{ Past 3 years } \\
\hline$<5.5$ & 42 & 31 & Reference & Reference \\
\hline $5.5-16.4$ & 40 & 20 & $1.10(0.71-1.71)$ & $0.84(0.47-1.48)$ \\
\hline $16.5-32.9$ & 29 & 22 & $0.71(0.44-1.15)$ & $1.06(0.61-1.85)$ \\
\hline $33.0+$ & 50 & 35 & $0.72(0.47-1.11)$ & $1.23(0.75-2.03)$ \\
\hline Trend $\mathrm{p}$ & & & 0.05 & 0.32 \\
\hline Homogeneity-of-trends $p$ & & & 0.04 & \\
\hline \multicolumn{5}{|c|}{$\begin{array}{l}\text { AVERAGE ANNUAL STRENOUS PHYSICAL } \\
\text { ACTIVITY } \\
\text { (MET-hours/week) }^{b}\end{array}$} \\
\hline \multicolumn{5}{|l|}{ Long-term } \\
\hline$<5.5$ & 44 & 28 & Reference & Reference \\
\hline $5.5-16.4$ & 42 & 25 & $1.02(0.67-1.57)$ & $1.06(0.61-1.84)$ \\
\hline $16.5-32.9$ & 30 & 25 & $0.73(0.45-1.17)$ & $1.22(0.70-2.12)$ \\
\hline $33.0+$ & 45 & 30 & $0.87(0.55-1.37)$ & $1.56(0.91-2.70)$ \\
\hline Trend $p$ & & & 0.34 & 0.10 \\
\hline Homogeneity-of-trends $p$ & & & 0.04 & \\
\hline \multicolumn{5}{|l|}{ Past 3 years } \\
\hline$<5.5$ & 73 & 57 & Reference & Reference \\
\hline $5.5-16.4$ & 23 & 16 & $0.89(0.56-1.44)$ & $0.97(0.55-1.70)$ \\
\hline $16.5-32.9$ & 18 & 14 & $0.79(0.47-1.33)$ & $1.27(0.70-2.32)$ \\
\hline $33.0+$ & 47 & 21 & $1.09(0.74-1.60)$ & $1.60(0.95-2.68)$ \\
\hline Trend $p$ & & & 0.82 & 0.08 \\
\hline Homogeneity-of-trends $p$ & & & 0.19 & \\
\hline
\end{tabular}

AVERAGE ANNUAL MODERATE +STRENUOUS PHYSICAL ACTIVITY

(MET-hours/week) 


\begin{tabular}{|c|c|c|c|c|}
\hline & \multicolumn{2}{|l|}{ No. cases } & \multicolumn{2}{|c|}{$\begin{array}{l}\text { Adjusted relative risk ( } 95 \% \\
\text { Confidence Interval) }\end{array}$} \\
\hline & $\mathrm{BMI}<25 \mathrm{~kg} / \mathrm{m}^{2}$ & BMI $\geq 25 \mathrm{~kg} / \mathrm{m}^{2}$ & BMI $<25 \mathrm{~kg} / \mathrm{m}^{2}$ & BMI $\geq 25 \mathrm{~kg} / \mathrm{m}^{2}$ \\
\hline \multicolumn{5}{|l|}{ Long-term } \\
\hline$<5.5$ & 30 & 21 & Reference & Reference \\
\hline $5.5-16.4$ & 51 & 24 & $0.83(0.53-1.30)$ & $0.67(0.37-1.20)$ \\
\hline $16.5-32.9$ & 39 & 35 & $0.59(0.37-0.96)$ & $1.05(0.61-1.82)$ \\
\hline $33.0+$ & 41 & 28 & $0.63(0.39-1.02)$ & $1.07(0.60-1.88)$ \\
\hline Trend $p$ & & & 0.03 & 0.35 \\
\hline Homogeneity-of-trends $p$ & & & 0.03 & \\
\hline \multicolumn{5}{|l|}{ Past 3 years } \\
\hline$<5.5$ & 49 & 37 & Reference & Reference \\
\hline $5.5-16.4$ & 44 & 29 & $0.87(0.58-1.31)$ & $1.04(0.64-1.70)$ \\
\hline $16.5-32.9$ & 30 & 21 & $0.62(0.40-0.99)$ & $1.12(0.65-1.91)$ \\
\hline $33.0+$ & 38 & 21 & $0.77(0.50-1.18)$ & $1.52(0.89-2.61)$ \\
\hline Trend $p$ & & & 0.11 & 0.16 \\
\hline Homogeneity-of-trends $p$ & & & 0.04 & \\
\hline
\end{tabular}

BMI: Body Mass Index; number of cases are fewer than those indicated in Table 2 due to missing data on BMI status.

${ }^{a}$ Stratified by age (years); adjusted for race (non-Hispanic White, Other/unknown) and oral contraceptive use (ever, never, unknown).

${ }^{b}$ Moderate physical activity and strenuous physical activity mutually adjusted for each other. 